\section{A tool, not a tyrant}

\section{Mott Greene}

6 selves a longing for mechanical explanation which has all the tenacity of original sin ... But nevertheless, just as the old monks struggled to subdue the flesh, so must the physicist struggle to subdue this sometimes nearly irresistible, but perfectly unjustifiable desire."

When Percy Bridgman wrote these words in the 1920s, he was preparing the way for a physics no longer unified by mechanics. Seventy-five years later, physicists still find it hard to abandon the search for mechanical explanation. Mechanisms and mechanics rule their minds and hearts: they still speak of quantum 'mechanics' even though there are no mechanics in it; the use of the word is a gesture of preferences and hope, without any particular physical meaning.

"Attempts to understand the motion of the electrons going around the nucleus by using mechanical laws," wrote Richard Feynman, "were a real failure: all kinds of predictions came out wrong."

The persistence of our desire for a mechanical explanation of every phenomenon may, however, not be only a preference or an ingrained habit of thought, but rather an injunction from nature, and the expression of our need to control, rather than merely to under- stand, the world. The criteria we use to settle scientific questions are clearly constructed to logical application. The search for a 'mechanism' may thus be part of a profound and ancient evolutionary strategy to help us survive, now built into our language and thought processes. There is more to our love of mechanism than our evolutionary past, however.

"I never satisfy myself until I can make a mechanical model of a thing," wrote Lord Kelvin, who required a mechanical picture as a metaphorical structure to guide his thinking. For him, a proper mechanical model was a tool of discovery. It was a structure of thought that would suggest new relations not at first apparent, and uncover aspects of reality not yet observed. Kelvin, and many before and after him, have spoken of the need for a mechanism when they meant to indicate that the business of explaining is incomplete until we discover the 'prime mover' in any physical situation. "Men are never satisfied," said Aristotle, "until they know the 'why' of a thing." To uncover a 'mechanism' is, for most of us, to move our ignorance of the world back one step towards that ever-elusive 'why'.

As the dictionary definition suggests, 'mechanism' is generally used as a synonym for 'cause', and the demand for a mechanism is an exhortation to pursue our inquiries into phenomena to the limits of our understanding. favour solutions that have a chance of techno-

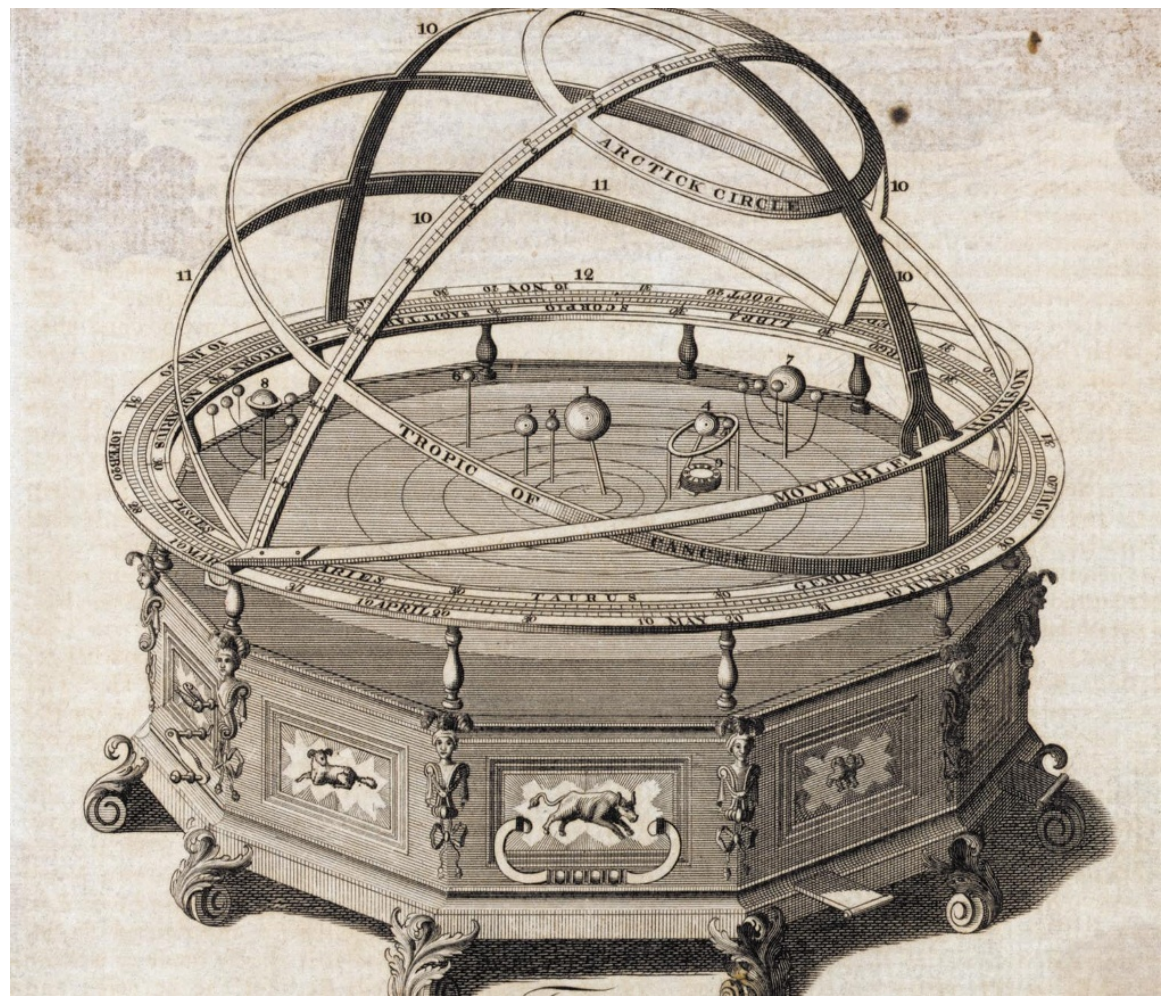

Mechanizing the planets: an orrery, a mechanical model of the Solar System.

\section{Mechanism}

\author{
"The machinery (lit. or fig.) by \\ means of which some particular \\ effect is produced." Oxford \\ English Dictionary.
}

For example, the hypothesis of continental drift was rejected in the 1920s for lack of such a mechanism, and its acceptance in the 1970s coincided with the development of the hypothesis of seafloor spreading, invoked as a mechanism for drift. Since then, inquiries into the subject have proceeded in search of the 'mechanism of the mechanism' - locating the cause of seafloor spreading in the convection of the Earth's mantle. Now, the search continues in an effort to locate a mechanism controlling the timing and location of convection: mechanisms within mechanisms, like nested Russian dolls.

The idea of mechanism is thus deeply lodged in us, and it serves us well, but we can place too much emphasis on it. This is an important point. Scientific theories (not mere hypotheses) based on abundant and convincing evidence and sound arguments have sometimes been forestalled for decades because they lacked a 'mechanism'. This was the fate of Darwin's theory for three-quarters of a century. The theory of evolution by natural selection was based on the existence of variation among members of a species, descent with modification from parent organisms, and differential survival of the offspring of different parents within a species - all of which could be easily observed. Darwin's inability to offer generally accepted mechanisms (causes) for these allowed not only his scientific opponents, but those theological opponents of any sort of evolution by any imaginable mechanism, to score debating points against the theory.

We might better say, with Bridgman, that for all its usefulness as a tool for thinking, our search for a mechanism must be regarded "no more seriously than is a mnemonic device, or any other artifice by which a man forces his mind to give him better service". We should also approach the question of mechanism with some humility, recalling Immanuel Kant's warning that "human reason ... is called upon to consider questions, which it cannot decline, as they are presented by its own nature, but which it cannot answer, because they transcend every faculty of mind."

Mott Greene is at the University of Puget Sound,

Tacoma, Washington 98416, USA.

\section{FURTHER READING}

Bridgman, P. W. The Logic of Modern Physics (Macmillan, New York, 1927).

Feynman, R. The Character of Physical Law (MIT Press, Cambridge, MA, 1965). 